\title{
Association between the bovine milk metabolome and rennet-induced coagulation properties of milk
}

\author{
Ulrik K. Sundekilde, ${ }^{* 1}$ Frida Gustavsson, $†$ Nina A. Poulsen, $\ddagger$ Maria Glantz, $†$ Marie Paulsson, $\dagger$ \\ Lotte B. Larsen,‡ and Hanne C. Bertram* \\ *Department of Food Science, Faculty of Science and Technology, Aarhus University, Kirstinebjergvej 10, DK-5792 Årslev, Denmark \\ †Department of Food Technology, Engineering and Nutrition, Lund University, PO Box 124, SE-221 00 Lund, Sweden \\ łDepartment of Food Science, Faculty of Science and Technology, Aarhus University, Blichers Allé 20, DK-8830 Tjele, Denmark
}

\section{ABSTRACT}

The milk metabolomes of 407 individual Swedish Red dairy cows were analyzed by nuclear magnetic resonance spectroscopy as part of the Danish-Swedish Milk Genomics Initiative. By relating these metabolite profiles to total milk protein concentration and rheological measurements of rennet-induced milk coagulation together using multivariate data analysis techniques, we were able to identify several different associations of the milk metabolome to technological properties of milk. Several novel correlations of milk metabolites to protein content and rennet-induced coagulation properties were demonstrated. Metabolites associated with the prediction of total protein content included choline, $N$-acetyl hexosamines, creatinine, glycerophosphocholine, glutamate, glucose 1-phosphate, galactose 1-phosphate, and orotate. In addition, levels of lactate, acetate, glutamate, creatinine, choline, carnitine, galactose 1-phosphate, and glycerophosphocholine were significantly different when comparing noncoagulating and well-coagulating milks. These findings suggest that the mentioned metabolites are associated with milk protein content and rennet-induced coagulation properties and may act as quality markers for cheese milk.

Key words: dairy milk, milk coagulation, milk metabolite, nuclear magnetic resonance spectroscopy, metabolomics

\section{INTRODUCTION}

Rennet-induced coagulation properties are crucial during cheese production, and, in addition to overall milk composition, the detailed contents of individual milk components, such as low-molecular-weight compounds, proteins, and minerals, are closely related to rennet-induced coagulation properties. It was shown

Received April 29, 2014

Accepted June 26, 2014.

${ }^{1}$ Corresponding author: uksundekilde@food.au.dk recently that $16 \%$ of all milk from Swedish Red (SR) cows was classified as noncoagulating (NC; Poulsen et al., 2013). Furthermore, we have previously shown that the low-molecular-weight metabolites in milk are correlated with rennet-induced coagulation properties (Sundekilde et al., 2011).

The technological quality of milk, such as rennetinduced coagulation properties, is known to be influenced by a range of different milk components. Some of the most important factors influencing coagulation properties are the total fat and protein contents, in addition to variability in protein composition and specific genetic variants of the caseins (Wedholm et al., 2006; Hallén et al., 2007; Jensen et al., 2012). Moreover, SCC, acidity (Ikonen et al., 2004), and variability in minor milk compounds, such as minerals and citrate (Udabage et al., 2001; Tsioulpas et al., 2007), have also been associated with differential milk coagulation properties. Additionally, oligosaccharides have been correlated with rennet-induced coagulation properties (Harzia et al., 2012). It has been shown previously that variations exist in coagulation properties in milk from different cows, where some cows produce well-coagulating (WC) milk and some produce poorly coagulating or NC milk (Ikonen et al., 1999; Glantz et al., 2010; Frederiksen et al., 2011). Coagulating properties can be expressed as both rennet coagulation time (RCT) and curd firming rate (CFR), which reflect how long it takes before a rennet-gel starts to form and at what rate the gel is built up, respectively. Thus, the technological quality of the milk is intricately associated with specific levels of different milk metabolites, minerals, $\mathrm{pH}$, and protein composition. In Denmark and Sweden, respectively, 47 and $26 \%$ of total milk production is used for cheese production (Landrug and Fødevarer, 2013; LRF Dairy Sweden, 2014), which highlights the importance of a high technological milk quality. However, despite this, few studies have investigated the link between the technological properties of milk and its minor compounds composition (Sundekilde et al., 2013a). We have previously reported that $\mathrm{NC}$ or poorly coagulating milk 
samples were correlated to concentrations of choline, carnitine, lactose, and citrate, as elucidated by nuclear magnetic resonance (NMR) spectroscopy and multivariate data analysis (Sundekilde et al., 2011).

In the present study, proton NMR spectroscopy of milk samples was used to explore milk metabolite profiles in 407 milk samples from the SR breed. The samples were also profiled for variations in milk protein content and for differences in rennet-induced coagulation properties. The aim of the present study was to investigate the relationship between the milk metabolome and important properties related to rennet-induced milk coagulation, including protein content, RCT, and CFR, using this large and unique sample set.

\section{MATERIALS AND METHODS}

\section{Milk Samples}

Milk samples from individual cows were collected as part of the Danish-Swedish Milk Genomics Initiative as described previously (Poulsen et al., 2012). In total, 407 milk samples from SR cows were collected from a total of 19 nonorganic herds in the south of Sweden (Poulsen et al., 2012). The cows included were selected from a scheme set up to maximize genetic variability, although cows were matched for parity (1-3) and lactation period (range of DIM: 18-427, mean: 187.81 d, SD: 78.12 d; Poulsen et al., 2013). All cows were housed in loose housing systems, fed a TMR according to standard practices during the indoor period, and milked twice or thrice a day. Immediately after milking, milk samples were cold stored at $4^{\circ} \mathrm{C}$ for $24 \mathrm{~h}$ during transport to Denmark. Each milk sample was then analyzed for contents of milk fat, protein, CN, and lactose by infrared spectroscopy (MilkoScan FT 2, Foss Analytical, Hillerød, Denmark) and for SCC using flow cytometry (Combifoss 5000, Foss Analytical) at a certified dairy analysis laboratory (Eurofins Steins Laboratory, Jönköping, Sweden). Samples for NMR experiments were frozen at $-80^{\circ} \mathrm{C}$.

\section{Rheological Analyses and Coagulation Properties}

Rheological analyses and the determination of coagulation properties were performed at $33^{\circ} \mathrm{C}$ as described earlier (Poulsen et al., 2013) using a ReoRox4 rheometer (Medirox, Nyköping, Sweden) based on oscillation rheometry. Essentially, $10 \mathrm{~mL}$ of milk was skimmed by centrifugation at $2,643 \times g$ for $30 \mathrm{~min}$ at $4^{\circ} \mathrm{C}$ and adjusted to $\mathrm{pH} 6.5 \pm 0.02$ with $10 \%$ ( $\mathrm{vol} / \mathrm{vol}$ ) lactic acid. Then, WC and NC scores were created based on information given by RCT and CFR. Noncoagulating samples $(\mathrm{n}=56)$ had $\mathrm{RCT}>3,600 \mathrm{~s}$ and $\mathrm{CFR}=0 \mathrm{~Pa} /$ min, whereas WC samples $(\mathrm{n}=44)$ had RCT $<1,080$ $\mathrm{s}$ and $\mathrm{CFR}>12.35 \mathrm{~Pa} / \mathrm{min}$. For additional studies, choline or carnitine (Sigma-Aldrich, St. Louis, MO) was added in increasing concentrations $(10,30$, and $60 \mathrm{mg} / \mathrm{L}$ ) to 10 skim milk samples from the resident Danish Holstein-Friesian herd at the Danish Cattle Research Center (KFC, Tjele, Denmark). After addition of choline or carnitine, the samples were stored for $24 \mathrm{~h}$ before the rheological analyses were performed.

\section{NMR Spectroscopy}

Proton NMR spectroscopy was performed as described previously (Sundekilde et al., 2013b). Briefly, the samples were filtered to remove residual lipids and protein using Amicon Ultra 0.5-mL $10 \mathrm{kDa}$ (Millipore, Billerica, MA) spin filters at $10,000 \times g$ for $15 \mathrm{~min}$. Then, $400 \mu \mathrm{L}$ of filtered sample was added to $200 \mu \mathrm{L}$ of $\mathrm{D}_{2} \mathrm{O}$ containing $0.025 \%$ sodium trimethylsilyl-[2,2,3,3${ }^{2} \mathrm{H}_{4}$ ]-1-propionate (TSP; Sigma-Aldrich) as an internal chemical shift reference. The ${ }^{1} \mathrm{H}$ NMR spectroscopy was performed at $298 \mathrm{~K}$ on a Bruker Avance III 600 spectrometer, operating at a ${ }^{1} \mathrm{H}$ frequency of $600.13 \mathrm{MHz}$, and equipped with a 5 -mm ${ }^{1} \mathrm{H}$ TXI probe (Bruker BioSpin, Ettlingen, Germany). The sample sequence was randomized before acquisition. Standard 1-dimensional spectra were acquired using a single $90^{\circ}$ pulse experiment with a relaxation delay of $5 \mathrm{~s}$. Water suppression was achieved by irradiating the water peak during the relaxation delay, and a total of 64 scans were collected into 32,768 data points spanning a spectral width of $12.15 \mathrm{ppm}$. All ${ }^{1} \mathrm{H}$ spectra were initially referenced to the TSP signal at $0 \mathrm{ppm}$. Before Fourier transformation, the data were multiplied by a $0.3-\mathrm{Hz}$ linebroadening function. The proton NMR spectra were phase and baseline corrected manually using Topspin 2.1 (Bruker Biospin). The NMR signals were assigned in accordance with existing literature (Sundekilde et al., 2013a), spike-in experiments, 2-dimensional NMR spectroscopy, and the Human Metabolome Database (Wishart et al., 2009).

\section{Uni- and Multivariate Data Analysis}

Milk samples with high SCC (>500,000 cells/mL; n $=6)$, missing rheological data $(\mathrm{n}=8)$, or with poor quality NMR spectra $(\mathrm{n}=15)$ were removed before multivariate data analysis. Thus, $378{ }^{1} \mathrm{H}$ NMR spectra of milk samples were aligned using Icoshift (Savorani et al., 2010) by co-shifting of the whole spectra according to the anomeric lactose proton at $5.23 \mathrm{ppm}$, followed by local shifting in 63 intervals. Residual water resonances and resonances stemming from the filtering procedure were removed. The proton NMR 
spectra were subdivided into $0.01 \mathrm{ppm}$ bins, reducing each spectrum into 994 separate variables in the regions 10.00-5.00, 4.72-3.76, and 3.63-0.5 ppm. Principal component analysis (PCA) and orthogonal projection to latent squares discriminant analysis (OPLS-DA) were performed to identify differences in metabolite profiles. Partial least squares (PLS) regression models were generated to address the variation in metabolites specifically associated with protein concentration. The PLS and OPLS-DA models were cross validated using segmentation with 10 splits. Root mean square error of cross validation (RMSECV) and $\mathrm{Q}^{2}$, the percent of variation of the training set predicted by the model according to cross validation, were measures of the model robustness. Important variables in the PLS regression were investigated using variable importance for the projection (VIP; Chong and Jun, 2005). Covariance was investigated by analysis of OPLS-DA regression coefficients back-transformed to original data and color coded by the loading weights (Cloarec et al., 2005). Test for OPLS-DA model statistical significance was performed by ANOVA of the cross-validated residuals (CV-ANOVA; Eriksson et al., 2008). The multivariate data analysis was performed using SIMCA-P +13 (Umetrics AB, Malmo, Sweden) and PLS Toolbox 6.5 (Eigenvector Research Inc., Wenatchee, WA). Alignment by Icoshift, binning, and analysis of OPLS-DA plots were performed in Matlab 7.13 using scripts developed in house (MathWorks Inc., Natick, MA). Univariate statistical significance was evaluated by Student's $t$-test using the Statistics Toolbox in Matlab 7.13 (MathWorks Inc.).

\section{RESULTS AND DISCUSSION}

In the present study, 407 individual SR milk samples were analyzed using ${ }^{1} \mathrm{H}$ NMR spectroscopy. The SR breed has recently been shown to have a high frequency of NC milk when analyzing individual milk samples (Poulsen et al., 2013). Thus, to examine the milk samples in more detail, milks from the SR breed included in the study of Poulsen et al. (2013) were analyzed for differences in the metabolite profile. Sample information, fat and protein contents, and rennet-induced coagulation properties of the milk samples are presented in Table 1. The median ${ }^{1} \mathrm{H}$ NMR spectrum of the milk samples is shown in Figure 1, with proton assignments corresponding to Table 2. The spectrum shown in Figure 1 is divided into 3 regions, where the region $10-5.8$ is enlarged 100 times and the region $2.48-0.8$ is enlarged 25 times compared with the central region. In total, 32 metabolites were assigned (Figure 1 and Table 2 ). The most abundant metabolite detected in milk by ${ }^{1} \mathrm{H}$ NMR spectroscopy was lactose, followed by citrate
Table 1. Descriptive statistics of protein, casein, and fat contents, and coagulation properties (rennet clotting time, RCT, and curd firming rate, CFR) of Swedish Red cows

\begin{tabular}{lcccc}
\hline Trait & Mean & SD & Minimum & Maximum \\
\hline Protein, \% & 3.66 & 0.36 & 2.92 & 5 \\
Casein, \% & 2.65 & 0.09 & 2.32 & 3.09 \\
Fat, \% & 4.13 & 0.86 & 1.34 & 8.62 \\
RCT, ${ }^{1}$ s & 1,243 & 296 & 614.5 & 2,858 \\
CFR, ${ }^{\text {Pa/min }}$ & 9.53 & 5.19 & 1.75 & 29.55 \\
\hline
\end{tabular}

${ }^{1}$ Mean value and standard deviation were calculated only on samples able to coagulate within $1 \mathrm{~h}$ of measurement.

and then carnitine (Figure 1). Many metabolites were present only in trace amounts, including fumarate, hippurate, acetate, formate, ornithine, valine, and fucose (Figure 1; Table 2).

An important objective of the present study was to investigate if the milk metabolite profile could be associated with the milk composition and rennet-induced coagulation properties of milk. Correlations between the milk metabolome and milk composition could reveal insight into the molecular mechanism of milk coagulation or physiological aspects of the milk, as an association between specific milk metabolites and proteins could provide insight into milk quality. Prediction of total protein content by using PLS regression on NMR data revealed a relatively high correlation (cross-validated $\mathrm{R}^{2}=0.60$ ) between the NMR features and protein content (Figure 2A). The PLS model was generated using 11 PLS components on 378 milk samples and 994 NMR features as described. Moreover, the model was cross validated as described, yielding an RMSECV of $0.23 \%$. The milk proteins were removed by filtration before NMR spectroscopy, thus the milk metabolites shown to have a high VIP score in Figure 2B were useful in prediction of milk protein content. Moreover, these metabolites were highly correlated with the milk proteins and as such could be used to elucidate physiological features of milk composition. The metabolites that had a strong influence on the PLS calibration model included choline, $\mathrm{N}$-acetyl hexosamines (glucosamine or galactosamine), creatinine, glycerophosphocholine (GPC), orotate, galactose 1-phosphate (Gal 1-P), glucose 1-phosphate (Glu 1-P), and glutamate (Figure 2B). The most influential metabolite for the PLS regression was choline (Figure 2B). To the best of our knowledge, no direct link between milk proteins and choline exists in the literature. $\mathrm{N}$-Acetyl hexosamines and glutamate were also important for model performance. $\mathrm{N}$-Acetyl hexosamines can originate from protein catabolism, as protein glycosylations may be cleaved off the proteins by the intracellular catabolic enzymatic system. However, a study of milk traits and milk metabolite profiles recently found that neither $N$-acetyl glucosamine nor 


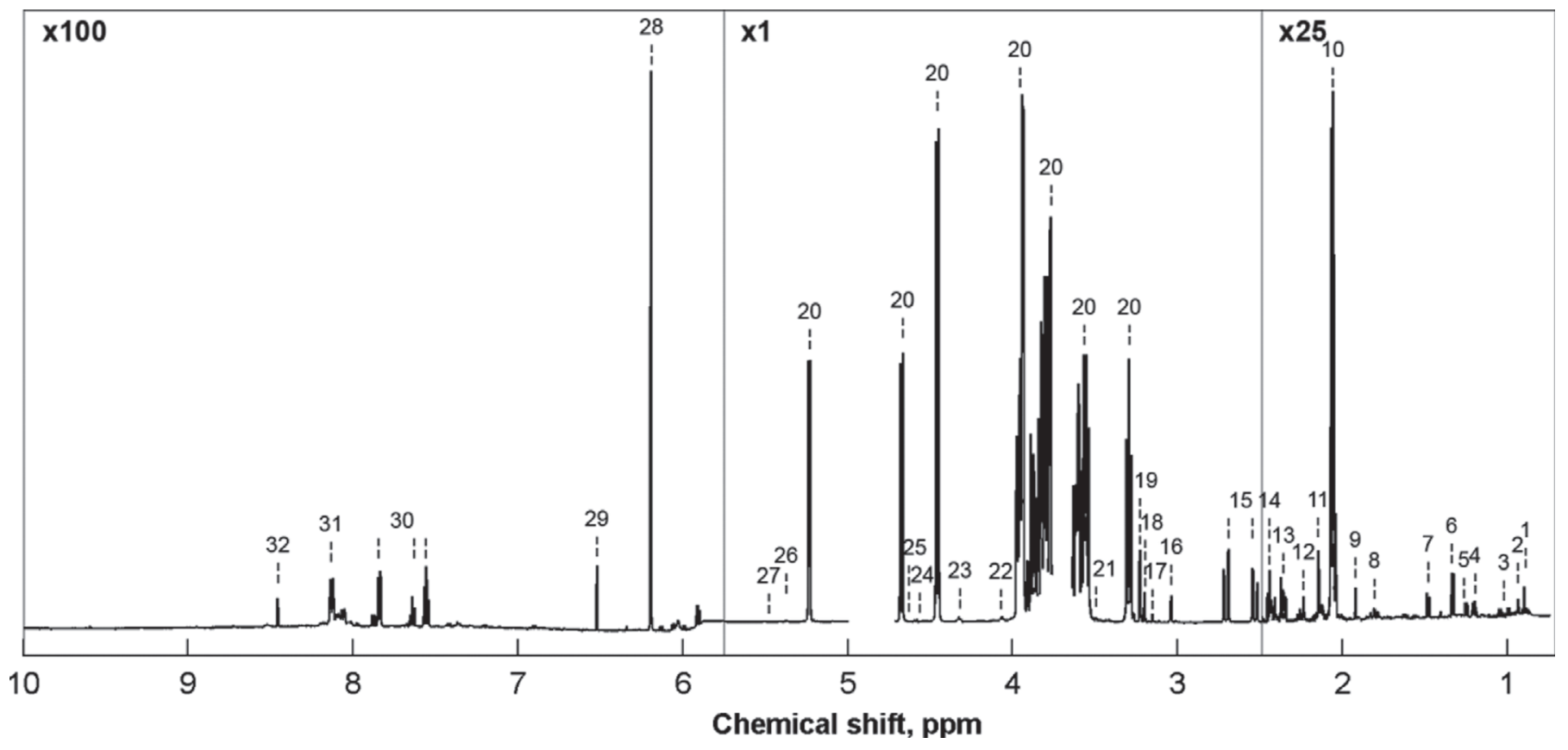

Figure 1. Median spectrum of milk samples $(\mathrm{n}=392)$ including assignments listed in Table 2. The region 10-5.8 is enlarged 100 times and the region 2.48-0.8 is enlarged 25 times compared with the central region.

Table 2. List of chemical shift values and proton assignments for milk metabolites numbered according to Figure 1

\begin{tabular}{|c|c|c|c|}
\hline ID & Metabolite & ${ }^{1} \mathrm{H}$ chemical shift & Assignment \\
\hline 1 & Butyrate & 0.90 & $\mathrm{CH}_{3}$ \\
\hline 2 & Isoleucine & 0.93 & $\delta-\mathrm{CH}_{3}$ \\
\hline 3 & Valine & $0.99,1.04$ & $\mathrm{CH}_{3}, \mathrm{CH}_{3}$ \\
\hline 4 & Ethanol & 1.17 & $\mathrm{CH}_{3}$ \\
\hline 5 & Fucose & 1.25 & $\mathrm{CH}_{3}$ \\
\hline 6 & Lactate & 1.32 & $\mathrm{CH}_{3}$ \\
\hline 7 & Alanine & 1.48 & $\mathrm{CH}_{3}$ \\
\hline 8 & Ornithine & 1.8 & $\gamma-\mathrm{CH}_{2}$ \\
\hline 9 & Acetate & 1.92 & $\mathrm{CH}_{3}$ \\
\hline 10 & $N$-acetyl hexosamines & 2.06 & $\mathrm{CH}_{3}$ \\
\hline 11 & Methionine & 2.15 & $\gamma-\mathrm{CH}_{2}, \mathrm{~S}-\mathrm{CH}_{3}$ \\
\hline 12 & Acetone & 2.24 & $\mathrm{CH}_{3}$ \\
\hline 13 & Glutamate & 2.36 & $\gamma-\mathrm{CH}_{2}$ \\
\hline 14 & Carnitine & 2.44 & $\mathrm{CH}_{2}$ \\
\hline 15 & Citrate & $2.52,2.72$ & $\mathrm{CH}_{2}, \mathrm{CH}_{2}$ \\
\hline 16 & Creatinine & 3.05 & $\mathrm{CH}_{3}$ \\
\hline 17 & Malonic acid & 3.11 & $\mathrm{CH}_{2}$ \\
\hline 18 & Choline & 3.18 & $3 \times \mathrm{CH}_{3}$ \\
\hline 19 & Carnitine & 3.21 & $3 \times \mathrm{CH}_{3}$ \\
\hline 20 & Lactose & Multiple $^{1}$ & - \\
\hline 21 & Phosphocholine & 3.58 & $\mathrm{~N}-\mathrm{CH}_{2}$ \\
\hline 22 & Phosphocholine & 4.16 & $\mathrm{O}-\mathrm{CH}_{2}$ \\
\hline 23 & Glycerophosphocholine & 4.32 & $\mathrm{~N}-\mathrm{CH}_{2}$ \\
\hline 24 & Galactose $\beta$ & 4.57 & $\mathrm{CH}-1$ \\
\hline 25 & Glucose $\beta$ & 4.65 & CH-1 \\
\hline 26 & Galactose 1-phosphate & 5.38 & CH-1 \\
\hline 27 & Glucose 1-phosphate & 5.51 & CH-1 \\
\hline 28 & Orotate & 6.2 & $\mathrm{CH}$ \\
\hline 29 & Fumarate & 6.52 & $\mathrm{CH}$ \\
\hline 30 & Hippurate & $7.54,7.64,7.84$ & $\mathrm{CH}_{2}-3,5 ; \mathrm{CH}-4 ; \mathrm{CH}_{2}-2,6$ \\
\hline 31 & Adenine & $8.12,8.13$ & $\mathrm{CH}-8, \mathrm{CH}-2$ \\
\hline 32 & Formate & 8.45 & $\mathrm{CH}$ \\
\hline
\end{tabular}

${ }^{1}$ For complete assignments of lactose protons, refer to Sundekilde et al. (2013a). 
A

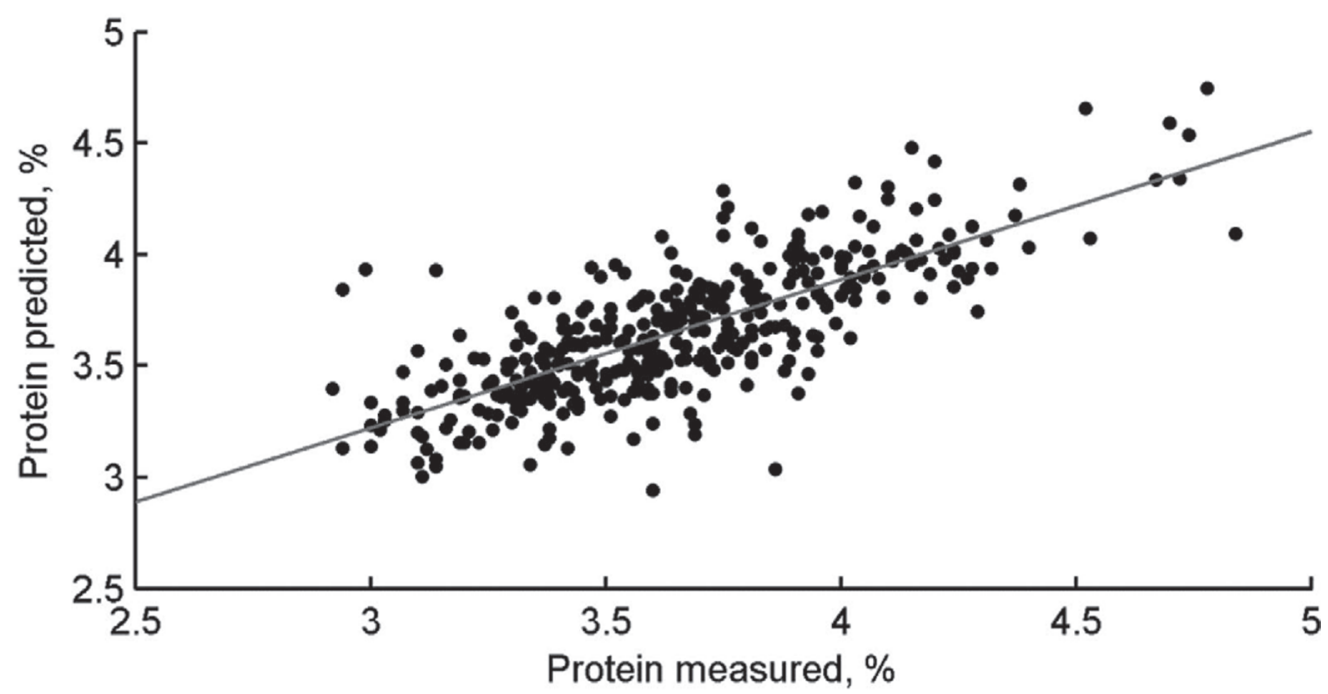

B

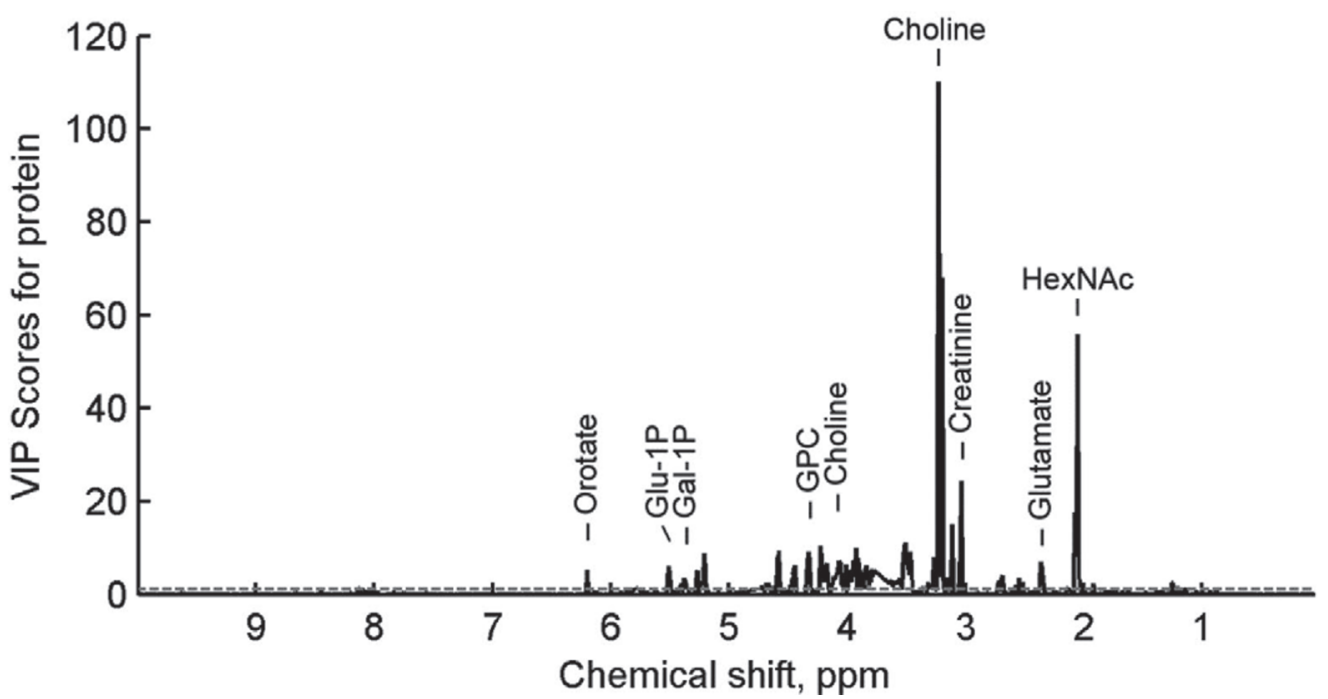

Figure 2. (A) Actual versus predicted plot of protein content (\%) obtained from an 11-component partial least squares (PLS) regression model established on Pareto-scaled nuclear magnetic resonance (NMR) data from 378 milk samples $\left(R^{2}=0.75\right.$, cross-validated $R^{2}=0.60$, root mean square error of cross validation $=0.23 \%$ ). (B) Corresponding variable importance for the projection (VIP) plot, giving an estimation of the importance of each variable in the PLS model. Gal-1P = galactose 1-phosphate; Glu-1P = glucose 1-phosphate; GPC = glycerophosphocholine; HexNAc $=N$-acetyl hexosamines

$\mathrm{N}$-acetyl galactosamine was associated with milk protein content (Melzer et al., 2013). This difference may be attributed to a difference in method of detection, as Melzer et al. (2013) used GC-MS, whereas the present study used NMR spectroscopy. The amino acid glutamate may result from proteolysis and is then reused in protein synthesis. Amino acids such as methionine and tyrosine have been shown to be positively correlated with milk protein content (Melzer et al., 2013). Another important metabolite in the prediction of protein content was creatinine (Figure 2B). Creatinine is the end product of creatine metabolism (Wyss and Kaddurah-Daouk, 2000) and is excreted through the urine. Variations in the milk content of orotate, Gal 1-P, GPC, lactate, and citrate were less important for the PLS regression model.

Rheological measurements showed a rather large variability in CFR and $\mathrm{RCT}$ within the $\mathrm{SR}$ breed (Table 1). Noncoagulating milk has been found to be more common in certain breeds; for example, $13 \%$ of Finnish Ayrshire cows have been reported to produce NC milk (Ikonen et al., 2004). For samples that were able to coagulate, PLS regression models with NMR features and CFR and RCT were examined (data not shown). However, neither of these models was able to describe the data with an acceptable predictive power 
(data not shown). This may be ascribed to the low variation in CFR and RCT when NC samples were left out of the sample set. Impaired coagulation properties (poorly coagulating or $\mathrm{NC}$ ) are important traits to address with respect to overall milk quality as it relates to cheese production. Thus, to examine the association between milk metabolites and technological properties of milk, the NC milk samples $(\mathrm{n}=56)$ were analyzed in more detail. For comparison, WC milk samples ( $\mathrm{n}=$ $44)$ were also selected. The protein content in the NC group $(3.62 \%$; SD: $0.32 \%)$ was significantly $(P<0.001)$ lower than that in the WC group (4.00\%; SD: $0.35 \%)$.
A PCA model based on the metabolite profiles of the $\mathrm{NC}$ and WC milk samples showed reasonable clustering of the 2 classes by principal component 2 and principal component 3 (Figure 3A). As the clustering was split on 2 or more components, an OPLS-DA model would simplify interpretation as uncorrelated variation for this clustering is discarded. Thus, an OPLS-DA model obtained on the same data as the PCA in Figure $3 \mathrm{~A}$ is shown in Figure $3 \mathrm{~B}$ and Figure $3 \mathrm{C}\left(\mathrm{Q}^{2}=0.52\right.$; CV-ANOVA indicated that the model was significant; $P<0.001)$. The predictive component encompassed $5.41 \%$ of the total variation in the data set (Figure
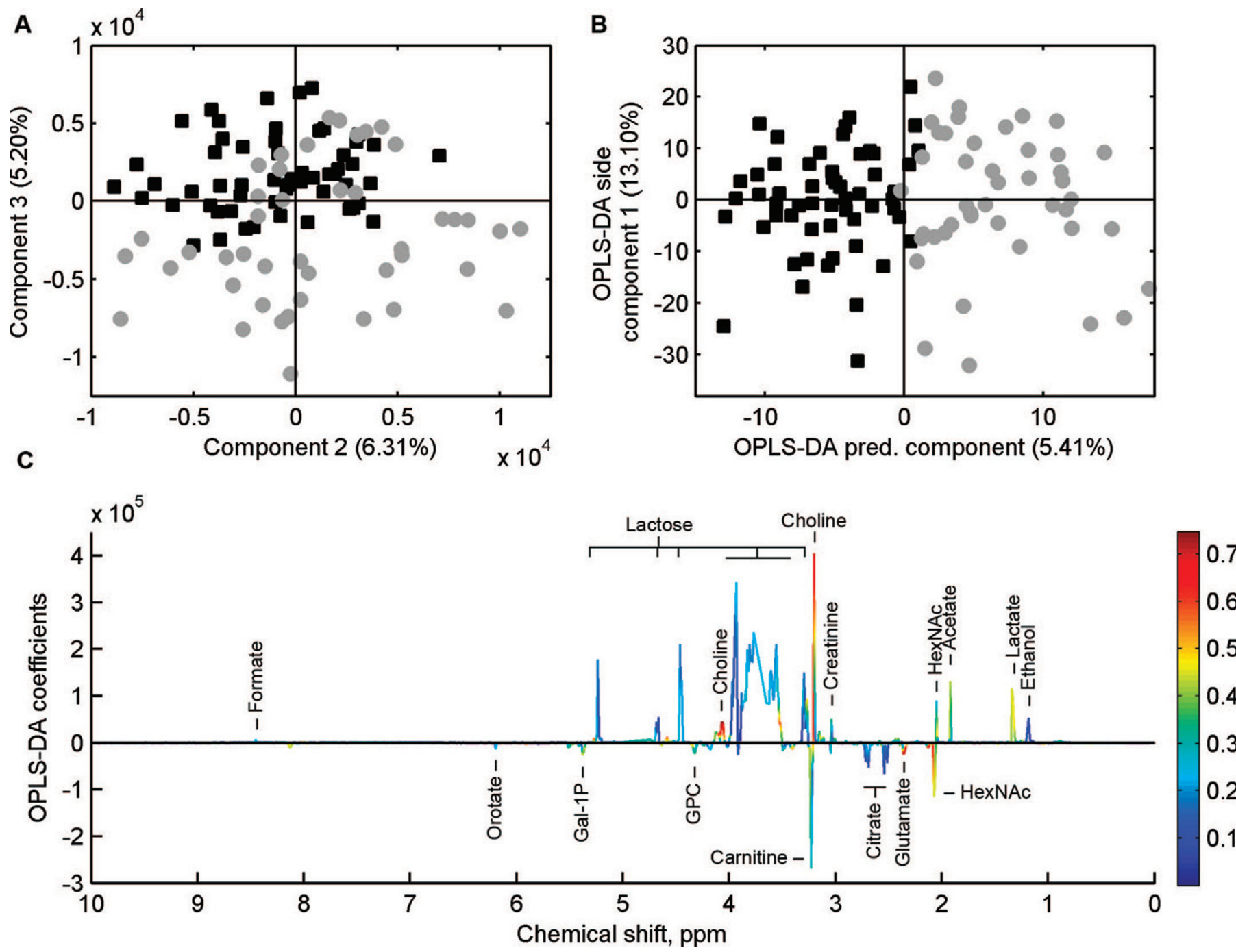

Figure 3. (A) Principal components analysis score plot of the second and third principal components of Pareto-scaled nuclear magnetic resonance (NMR) data from 100 milk samples of Swedish Red cows; (B) orthogonal projection to latent squares discriminant analysis (OPLS$\mathrm{DA})$ score plot of a model of the unit variance scaled data in $(\mathrm{A})$; black squares represent noncoagulating $(\mathrm{n}=56)$ and gray dots represent well-coagulating $(\mathrm{n}=44)$ milk samples; $(\mathrm{C})$ OPLS-DA coefficients plot of the model shown in (B) back-transformed. Each variable has been colored according to the OPLS-DA loadings (correlation between NMR variable and coagulation). Gal-1P = galactose 1-phosphate; GPC $=$ glycerophosphocholine; HexNAc $=N$-acetyl hexosamines. Color version available in the online PDF. 


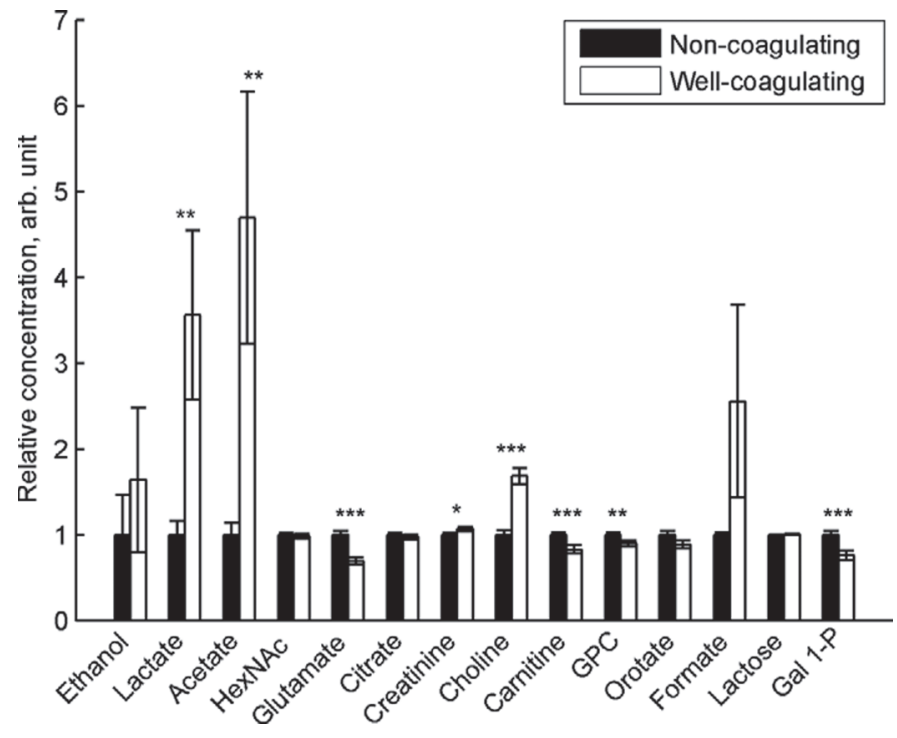

Figure 4. Relative quantification of metabolites from integration of nuclear magnetic resonances (NMR). Black bars represent noncoagulating $(\mathrm{n}=56)$ milk samples and white bars represent milk samples with good coagulation $(\mathrm{n}=44)$ properties. Mean values \pm SEM are given; significant differences are indicated by ${ }^{*} P<0.05$, ${ }^{*} P P<0.01$, and ${ }^{* * *} P<0.001$. Gal-1P = galactose 1 -phosphate; GPC $=$ glycerophosphocholine; HexNAc $=N$-acetyl hexosamines; arb. unit $=$ arbitrary unit.

3B). The coefficient plot specified that choline, carnitine, acetate, lactose, lactate, $N$-acetyl hexosamines, creatinine, ethanol, citrate, Gal 1-P, GPC, orotate, glutamate, and formate were the important metabolites for the observed clustering by $\mathrm{NC}$ and $\mathrm{WC}$ (Figure 3C). Choline, lactose, acetate, lactate, creatinine, ethanol, and formate were found to be present at higher levels in WC milk, whereas carnitine, citrate, Gal 1-P, GPC, orotate, and glutamate were found to be present at higher levels in NC milk. These metabolites were also analyzed by univariate statistics by comparing the mean values of the 2 sample groups as described. Thus, intensities were determined by integration of selected resonances of the metabolites (Table 2) in the NMR spectra of the NC and WC milk samples (Figure 4). The relative concentrations of metabolites were set to 1 in NC milk samples and scaled accordingly in WC samples. Relative concentrations of lactate $(P=0.005)$, acetate $(P=0.006)$, creatinine $(P=0.027)$ and choline $(P<0.001)$ were found to be significantly increased in WC milk samples, whereas glutamate $(P<0.001)$, carnitine $(P<0.001)$, GPC $(P=0.01)$, and Gal 1-P $(P$ $<0.001)$ were found in significantly increased levels in NC milk samples. Lactate and acetate were increased 3.5- and 4.5-fold in WC milk samples, respectively (Figure 4). Choline was increased 2-fold in WC milk samples (Figure 4). No significant differences in the levels of ethanol, $\mathrm{N}$-acetyl hexosamines, citrate, orotate, formate, or lactose were observed in $\mathrm{NC}$ and $\mathrm{WC}$ milk. For ethanol, acetate, lactate, and formate, large standard errors of the mean were observed (Figure 4). This finding could indicate bacterial contamination in a few samples as these 4 metabolites can be associated with bacterial metabolism. Bacterial contamination in milk would contribute to overall milk coagulation ability. The protein content was found to be lower in NC milk compared with WC milk. However, the small difference between the 2 sets of milk samples cannot explain the occurrence of NC milk. Accordingly, some overlap exists between the associations between milk metabolites and protein and between milk metabolites and NC.

We previously identified that choline and carnitine were correlated with rennet-induced coagulation properties (Sundekilde et al., 2011). The present findings showing that choline is increased and carnitine is decreased in WC milk are in agreement with previous results (Sundekilde et al., 2011). Furthermore, the multivariate data analysis in the present study suggests that choline and carnitine could be indicators of rennet-induced coagulation properties and $\mathrm{NC}$ milk. Choline and carnitine may have an effect, direct or indirect, on these properties. Thus, to investigate the effect of these metabolites on rennet-induced coagulation, increasing amounts of choline or carnitine were added to milk samples and the effect on coagulation was assessed (Figure 5). Normal levels of choline and carnitine in bovine milk are 200 to $400 \mu \mathrm{mol} / \mathrm{L}$ (Holmes-McNary et al., 1996) and 130-360 $\mu \mathrm{mol} / \mathrm{L}$ (Woollard et al., 1999), respectively. Figure 5 shows that addition of choline or carnitine negatively affected rennet-induced coagulation. As the multivariate data analysis showed a positive association between choline levels and coagulation, it is surprising that addition of choline had a negative effect on milk coagulation. In contrast, the effect of addition of carnitine on coagulation is in agreement with results from the multivariate models (Figure 5). Consequently, choline in milk seems to be indirectly associated with coagulation properties, whereas carnitine may have a more direct effect on rennet-induced coagulation. As choline may originate from phosphatidylcholine and sphingomyelin, 2 classes of phospholipid that are present in cell membranes, the association between choline and rennet-induced coagulation may be ascribed to choline acting as an indicator of milk fat globule membranes; therefore, the association might be ascribed to an effect of milk fat globule size on rennet-induced coagulation. Overall, our results indicate that these 2 metabolites could be useful as indicators of overall rennet-induced coagulation and of NC properties. However, carnitine has also been shown to be increased in milk samples from 2 different breeds that were characterized by WC properties 

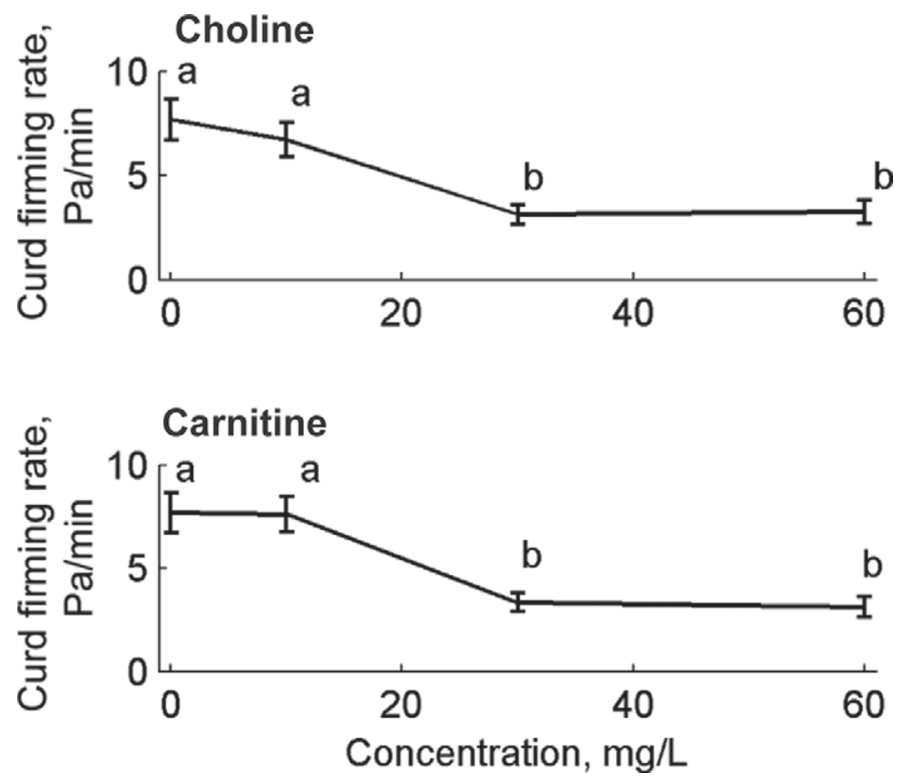

Figure 5. Response on milk curd firming rate on the addition of (A) choline and $(\mathrm{B})$ carnitine. Mean values $(\mathrm{n}=8) \pm \mathrm{SEM}$ are given. Significant differences $(P<0.05)$ are indicated by letters.

(Harzia et al., 2012). The role directly played by carnitine in the rennet-induced coagulation process thus remains unclear. Interestingly, choline and carnitine in bovine milk were both found to have high heritability (Buitenhuis et al., 2013). Accordingly, changes in the levels of metabolites in milk could be pursued by selective breeding. However, more detailed knowledge of the effects of choline and carnitine on milk coagulation is needed to determine whether this is an interesting path to pursue in relation to milk quality.

\section{CONCLUSIONS}

The use of NMR-based metabolomics in the elucidation of metabolites in milk samples with differential coagulation properties allowed us to identify novel associations between metabolite profile and rennet-induced coagulation properties of bovine milk. Multivariate data analyses revealed that NMR data obtained from milk could discriminate between milk samples according to total protein content and coagulation properties. Metabolites associated with the prediction of protein content included choline, $\mathrm{N}$-acetyl hexosamines, creatinine, GPC, glutamate, Glu-1P, Gal-1P, and orotate. Furthermore, the levels of lactate, acetate, glutamate, creatinine, choline, carnitine, and GPC were found to be associated with $\mathrm{NC}$ properties and were significantly different between $\mathrm{NC}$ and WC milks. Hence, these metabolites could be used as indicators for milk quality and our results have identified novel information about milk metabolites that are important for total protein content and rennet-induced coagulation properties. Further experiments designed to elucidate the role played by these metabolites in processes related to cheese production could be of great interest.

\section{ACKNOWLEDGMENTS}

The authors thank the Danish Strategic Research Council (Copenhagen, Denmark) through the project "Milk Genomics - Impact of genes for variation in milk composition and quality," the Danish Research Council FTP (Copenhagen, Denmark) through the project "Advances in Food Quality and Nutrition Research Through Implementation of Metabolomic Strategies," The Swedish Farmers' Foundation for Agricultural Research (SLF; Stockholm, Sweden), Arla Foods amba (Viby J, Denmark), and the Danish Cattle Federation (Aarhus, Denmark) for financial support. The Danish sampling and analysis team at the Danish-Swedish Milk Genomics Initiative are gratefully acknowledged for their excellent technical assistance.

\section{REFERENCES}

Buitenhuis, A. J., U. K. Sundekilde, N. A. Poulsen, H. C. Bertram, L. B. Larsen, and P. Sørensen. 2013. Estimation of genetic parameters and detection of quantitative trait loci for metabolites in Danish Holstein milk. J. Dairy Sci. 96:3285-3295.

Chong, I. G., and C. H. Jun. 2005. Performance of some variable selection methods when multicollinearity is present. Chemom. Intell. Lab. Syst. 78:103-112.

Cloarec, O., M. E. Dumas, J. Trygg, A. Craig, R. H. Barton, J. C. Lindon, J. K. Nicholson, and E. Holmes. 2005. Evaluation of the orthogonal projection on latent structure model limitations caused by chemical shift variability and improved visualization of biomarker changes in ${ }^{1} \mathrm{H}$ NMR spectroscopic metabonomic studies. Anal. Chem. 77:517-526.

Eriksson, L., J. Trygg, and S. Wold. 2008. CV-ANOVA for significance testing of PLS and OPLS models. J. Chemometr. 22:594-600.

Frederiksen, P., M. Hammershøj, M. Bakman, P. Andersen, J. Andersen, K. Qvist, and L. Larsen. 2011. Variations in coagulation properties of cheese milk from three Danish dairy breeds as determined by a new free oscillation rheometry-based method. Dairy Sci. Technol. 91:309-321.

Glantz, M., T. G. Devold, G. E. Vegarud, H. Lindmark-Månsson, H. Stålhammer, and M. Paulsson. 2010. Importance of casein micelle size and milk composition for milk gelation. J. Dairy Sci. 93:1444-1451.

Hallén, E., T. Allmere, J. Naslund, A. Andrén, and A. Lunden. 2007. Effect of genetic polymorphism of milk proteins on rheology of chymosin-induced milk gels. Int. Dairy J. 17:791-799.

Harzia, H., K. Kilk, I. Jõudu, M. Henno, O. Kärt, and U. Soomets. 2012. Comparison of the metabolic profiles of noncoagulating and coagulating bovine milk. J. Dairy Sci. 95:533-540.

Holmes-McNary, M. Q., W. L. Cheng, M. H. Mar, S. Fussell, and S. H. Zeisel. 1996. Choline and choline esters in human and rat milk and in infant formulas. Am. J. Clin. Nutr. 64:572-576.

Ikonen, T., K. Ahlfors, R. Kempe, M. Ojala, and O. Ruottinen. 1999. Genetic parameters for the milk coagulation properties and prevalence of noncoagulating milk in Finnish dairy cows. J. Dairy Sci. $82: 205-214$. 
Ikonen, T., S. Morri, A.-M. Tyrisevä, O. Ruottinen, and M. Ojala. 2004. Genetic and phenotypic correlations between milk coagulation properties, milk production traits, somatic cell count, casein content, and pH of milk. J. Dairy Sci. 87:458-467.

Jensen, H. B., J. W. Holland, N. A. Poulsen, and L. B. Larsen. 2012. Milk protein genetic variants and isoforms identified in bovine milk representing extremes in coagulation properties. J. Dairy Sci. 95:2891-2903.

Landrug \& Fødevarer. 2013. Dairy statistics 2012. Landrug \& Fødevarer, Copenhagen, Denmark.

LRF Dairy Sweden. 2014. Dairy statistics. LRF Dairy Sweden, Stockholm. Accessed Apr. 28, 2014. http://www.lrf.se/Medlem/Foreta gande/LRF-Mjolk/Statistik/Tillverkning/Mjolkens-anvandning/.

Melzer, N., D. Wittenburg, S. Hartwig, S. Jakubowski, U. Kesting, L. Willmitzer, J. Lisec, N. Reinsch, and D. Repsilber. 2013. Investigating associations between milk metabolite profiles and milk traits of Holstein cows. J. Dairy Sci. 96:1521-1534.

Poulsen, N. A., H. P. Bertelsen, H. B. Jensen, F. Gustavsson, M Glantz, H. Lindmark Månsson, A. Andrén, M. Paulsson, C. Bendixen, A. J. Buitenhuis, and L. B. Larsen. 2013. The occurrence of noncoagulating milk and the association of bovine milk coagulation properties with genetic variants of the caseins in 3 Scandinavian dairy breeds. J. Dairy Sci. 96:4830-4842.

Poulsen, N. A., F. Gustavsson, M. Glantz, M. Paulsson, L. B. Larsen, and M. K. Larsen. 2012. The influence of feed and herd on fatty acid composition in three dairy breeds (Danish Holstein, Danish Jersey and Swedish Red). J. Dairy Sci. 95:6362-6371.

Savorani, F., G. Tomasi, and S. B. Engelsen. 2010. Icoshift: A versatile tool for the rapid alignment of 1D NMR spectra. J. Magn. Reson. 202:190-202

Sundekilde, U. K., P. D. Frederiksen, M. R. Clausen, L. B. Larsen, and H. C. Bertram. 2011. Relationship between the metabolite profile and technological properties of bovine milk from two dairy breeds elucidated by NMR-based metabolomics. J. Agric. Food Chem. 59:7360-7367.

Sundekilde, U. K., L. B. Larsen, and H. C. Bertram. 2013a. NMRbased milk metabolomics. Metabolites 3:204-222.

Sundekilde, U. K., N. A. Poulsen, L. B. Larsen, and H. C. Bertram. 2013b. Nuclear magnetic resonance metabonomics reveals strong association between milk metabolites and somatic cell count in bovine milk. J. Dairy Sci. 96:290-299.

Tsioulpas, A., M. J. Lewis, and A. S. Grandison. 2007. Effect of minerals on casein micelle stability of cows' milk. J. Dairy Res. 74:167-173

Udabage, P., I. R. McKinnon, and M. A. Augustin. 2001. Effects of mineral salts and calcium chelating agents on the gelation of renneted skim milk. J. Dairy Sci. 84:1569-1575.

Wedholm, A., L. B. Larsen, H. Lindmark-Månsson, A. H. Karlsson, and A. Andrén. 2006. Effect of protein composition on the cheesemaking properties of milk from individual dairy cows. J. Dairy Sci. 89:3296-3305.

Wishart, D. S., C. Knox, A. C. Guo, R. Eisner, N. Young, B. Gautam, D. D. Hau, N. Psychogios, E. Dong, S. Bouatra, R. Mandal, I. Sinelnikov, J. Xia, L. Jia, J. A. Cruz, E. Lim, C. A. Sobsey, S. Shrivastava, P. Huang, P. Liu, L. Fang, J. Peng, R. Fradette, D. Cheng, D. Tzur, M. Clements, A. Lewis, A. De Souza, A. Zuniga, M. Dawe, Y. Xiong, D. Clive, R. Greiner, A. Nazyrova, R. Shavkhutdinov, L. Li, H. J. Vogel, and I. Forsythe. 2009. HMDB A knowledgebase for the human metabolome. Nucleic Acids Res. 37(Database issue):D603-D610.

Woollard, D. C., H. E. Indyk, and G. A. Woollard. 1999. Carnitine in milk: A survey of content, distribution and temporal variation. Food Chem. 66:121-127.

Wyss, M., and R. Kaddurah-Daouk. 2000. Creatine and creatinine metabolism. Physiol. Rev. 80:1107-1213. 